\title{
Exogenous oestradiol benzoate induces male mice azoospermia through modulation of oxidative stress and testicular metabolic cooperation
}

\author{
JIANGHUA LE $^{1 *}$, XIAOCAN LEI ${ }^{2 *}$, YANPING REN ${ }^{2 *}$, ZHIPENG LI $^{3 *}$, HAOYAN TU ${ }^{2}$, \\ FANGYA DING $^{1}$, XIAODONG YI ${ }^{2}$, YI ZHOU ${ }^{2}$, QINGYOU LIU $^{3}$ and SHUN ZHANG ${ }^{1}$ \\ ${ }^{1}$ Department of Reproductive Medical Center, The Affiliated Hospital of Guilin Medical University, Guilin, Guangxi 541001; \\ ${ }^{2}$ Department of Histology and Embryology, School of Basic Medical Sciences, Zunyi Medical University, \\ Zunyi, Guizhou 563006; ${ }^{3}$ State Key Laboratory for Conversation and Utilization of Subtropical \\ Agro-Bioresources, Guangxi University, Nanning, Guangxi 530004, P.R. China
}

Received September 11, 2018; Accepted March 20, 2019

DOI: $10.3892 / \mathrm{mmr} .2019 .10169$

\begin{abstract}
In most cases, exogenous oestradiol benzoate (EB) inhibits spermatogenesis, however, the mechanism underlying this process has not been fully elucidated. The present study investigated the effect of EB on redox equilibrium and glycometabolism in mouse testes. Male Kunming mice were divided into 3 groups and injected with 0,5 and $10 \mathrm{mg} / \mathrm{kg}$ EB, respectively. Histological analysis revealed no sperm and far fewer spermatogenic cells in the testes of EB-treated mice. Additionally, transmission electron microscopy revealed that mitochondria in Sertoli cells were transformed to vacuoles with irregular cristae in the EB-treated group. EB also significantly decreased the activities and mRNA expression of catalase, superoxide dismutase, and glutathione peroxidase and increased the activity of nitric oxide synthase and nitric oxide concentration in the testes compared with the control. These results indicated that oxidative damage was caused by EB treatment. With regard to glycometabolism, ATP content and activities of hexokinase and pyruvate kinase were significantly reduced in the EB-treated group. Although glucose and pyruvate concentrations were significantly increased
\end{abstract}

Correspondence to: Dr Qingyou Liu, State Key Laboratory for Conversation and Utilization of Subtropical Agro-Bioresources, Guangxi University, 100 Daxue Road, Nanning, Guangxi 530004, P.R. China

E-mail: qyliu2002@gmail.com

Dr Shun Zhang, Department of Reproductive Medical Center, The Affiliated Hospital of Guilin Medical University, 15 Lequn Road, Guilin, Guangxi 541001, P.R. China

E-mail: artzhangshun@glmc.edu.cn

${ }^{*}$ Contributed equally

Key words: oestradiol benzoate, mechanism, metabolism, spermatogenic cells by EB treatment, levels of lactate, the main energy source of spermatogenic cells, were unchanged. Monocarboxylate transporter 2 (MCT2) and MCT4, which are responsible for lactate transportation, were downregulated by EB. In conclusion, the results of the present study indicated that azoospermia induced by EB in male mice was associated with oxidative damage and the disorder of testicular metabolic cooperation.

\section{Introduction}

The oestrogen steroid hormone $17 \beta$-oestradiol (E2) is essential for normal spermatogenesis, while a surplus of oestrogen along with a lack of testosterone usually causes infertility $(1,2)$. The general human population is exposed to many chemicals. Among them, oestrogenic and other endocrine disruptors (EDs) have been found to lead to a decline in male reproductive ability (3). Accumulated evidence has revealed that exposure to endocrine disruptors is associated with reduced semen quality and impaired fertility in men, as illustrated by slow development of gonad testis and epididymis as well as testicular atrophy $(4,5)$. Bisphenol A (BPA) is the most widely used and well-studied endocrine disruptor and has been implicated in the pathogenesis of male reproductive disability (6). High plasma BPA levels have been found in men with infertility, and plasma BPA level is negatively correlated with sperm concentration and total sperm count (7). Certain mechanisms by which exogenous oestrogen destroys male fertility have been revealed, such as the dysfunction of the hypothalamic-pituitary-testicular axis, inhibition of germ cell proliferation, germ cell apoptosis, and testicular oxidative stress (8). Oestradiol benzoate (EB) has been widely used to investigate the oestrogen-like effects of various EDs, which can eliminate the interference of other types of ED toxicity $(9,10)$. Our previous study revealed that EB disrupted spermatogenesis and induced infertility in male mice through its effects on apoptosis and oestrogen receptor signaling pathways (11). During the previous study, we inadvertently determined that EB interferes with testicular metabolic cooperation, but the underlying mechanism is largely unknown. 
Cellular energy metabolism affects various physiological and pathological processes $(12,13)$. The spermatogenesis process is sensitive to changes in energy metabolism. Sertoli cells (SCs) are pivotal to spermatogenesis by providing nutritional support to germ cells throughout their development. SCs preferentially export lactate to germ cells, which utilise lactate as their main energy substrate (14). In vitro studies have revealed that E2 controls glucose uptake and lactate production in SCs by regulating glycolysis-related transporters [e.g., glucose transporter 3 (GLUT3)] and enzymes [e.g., lactate dehydrogenase (LDH)] at the transcriptional level $(15,16)$. Therefore, it was hypothesized that EB likely modulates the glycolytic process in the testis, thereby inducing male infertility. The present study investigated the expression levels of glycolysis-related factors [including GLUT3, monocarboxylate transporter 2 (MCT2), MCT4, and LDH] and the activity of rate-limiting enzymes in mice.

\section{Materials and methods}

Animals and treatments. In total, 60 male Kunming mice (age, 4 weeks; weight, $25 \mathrm{~g}$ ) were purchased from the Laboratory Animal Center of the Third Military Medical University (Chongqing, China). The mice were raised in specific pathogen-free animal rooms with free access to a rodent diet and water. Housing conditions comprised a temperature-controlled polysulfone cage $\left(23-25^{\circ} \mathrm{C}\right)$ under a 12-h light/dark cycle.

All the mice were randomly divided into a control group and 2 treatment groups (20 animals/group). The treatment groups were intramuscularly injected with EB (Hangzhou Pharmaceutical Factory, Hangzhou, Zhejiang, China) at a concentration of 5 or $10 \mathrm{mg} / \mathrm{kg}$ body weight. This method was described in a previous study (17). The control group was injected with an equal quantity $(150 \mu \mathrm{l})$ of corn oil (COFCO Grain Factory, Chongqing, China). The injection was performed every other day for 4 weeks. The testes were immediately excised from euthanised mice at the end of the experiments and then trimmed of fat and connective tissue. One of the testes from each group was fixed in Bouin's or 2.5\% glutaraldehyde for histological analysis. The other testis was frozen in liquid nitrogen for biochemical and RNA detection. Cauda epididymis samples were collected for sperm counts. The present study was approved and monitored by the Animal Experiments Ethical Review Committee of Zunyi Medical University (Zunyi, China) (no. ZMU210500326). All procedures strictly adhered to the National Institutes of Health guidelines for the care and use of animals (18).

Sperm and testicular cell count. Sperm counts were obtained as previously described (19). The caudal epididymis was dissected and placed in $500 \mu \mathrm{l}$ of saline media heated to $37^{\circ} \mathrm{C}$, and then splayed openly using a back-cutting method. To give sperm time to escape into liquid, the caudal epididymis was left undisturbed for $30 \mathrm{sec}$. Subsequently, the number of sperm was assessed using a haemocytometer under a light microscope (Olympus, Tokyo, Japan) and expressed as 10\%/100 mg of epididymal weight.

Testes were stained with haematoxylin and eosin (H\&E) and haematoxylin-periodic acid-Schiff (PAS). Germ cells at stage VII of the seminiferous cycle, including spermatogonia, spermatocytes, and step 7 spermatids in 30 round seminiferous tubules per testicle (20), were counted using a conventional light microscope (Leica Microsystems GmbH, Wetzlar, Germany).

Transmission electron microscopy (TEM). For TEM, the testis samples were cut into pieces $(2 \times 2 \mathrm{~mm})$ and fixed in $2.5 \%$ glutaraldehyde $(\mathrm{pH}=7.4)$ for $6-8 \mathrm{~h}$ at $4^{\circ} \mathrm{C}$. Next, they were washed and fixed in $2 \% \mathrm{OSO}_{4}$ for $1 \mathrm{~h}$ at $4^{\circ} \mathrm{C}$. The tissue was finally dehydrated with alcohol solutions ascending in concentration gradient and embedded in araldite CY212. Semithin sections $(1 \mu \mathrm{m})$ were cut and stained with toluidine blue. Ultrathin sections $(60-70 \mathrm{~nm})$ were cut and stained with uranyl acetate and alkaline lead citrate.

Assessment of oxidative stress in the testis. Oxidative stress in the testis was detected as previously described (21). In brief, the testis was homogenized in $0.8 \%$ sodium chloride solution (pH 7.4) containing $0.01 \mathrm{~mol} / \mathrm{l}$ Tris- $\mathrm{HCl}, 1 \mathrm{mmol} / 1$ EDTA-2Na, and $0.01 \mathrm{~mol} / 1$ sucrose, with a glass homogenizer according to the weight-to-volume ratio of $1 \mathrm{~g}: 9 \mathrm{ml}$. After centrifugation of the homogenate at $839 \mathrm{xg}$ for $15 \mathrm{~min}$ at $4^{\circ} \mathrm{C}$, the supernatant was preserved. The activities of catalase (CAT), superoxide dismutase (SOD), glutathione peroxidase (GPx), nitric oxide synthase (NOS), malondialdehyde (MDA) and nitric oxide (NO) content were specifically detected by colorimetric assay at different absorbable wavelengths as the purchased kit (Nanjing Jiancheng Bioengineering Institute, Nanjing, China) indicated.

High performance liquid chromatography (HPLC). Testis tissue was rapidly frozen in liquid nitrogen and homogenized into powder. Adenosine phosphates were extracted from the powder with $10 \mu \mathrm{l} / \mathrm{mg}$ of $0.1 \mathrm{M}$ perchloric acid in an ice bath for $1 \mathrm{~min}$. The extraction mixture was centrifuged for $20 \mathrm{~min}$ at $5,031 \mathrm{x} \mathrm{g}$, and the supernatant was removed by paper filtration. The filtrate solution was filtered again through a $0.45-\mathrm{mm}$ filter. HPLC separation was achieved using continuous gradient elution as follows: Solution A, methanol; solution $\mathrm{B}, 0.1 \mathrm{M} \mathrm{NaH}_{2} \mathrm{PO}_{4}$ and $0.1 \mathrm{M} \mathrm{Na}_{2} \mathrm{HPO}_{4}$ mixed at a volume ratio of 9:1 and $10 \mathrm{mM}$ tetrabutylammonium sulphate; solution $\mathrm{A} / \mathrm{B}=12 / 88$. The flow rate of the mobile phase was $0.6 \mathrm{ml} / \mathrm{min}$, while the injection volume was $5 \mu 1$. Total retention time was $\sim 5 \mathrm{~min}$, and the gradient was run for 6 min to ensure full separation. The concentration of ATP was determined using the external standard method. Data were expressed as means of three repeat determinations.

Measurement of rate-limiting enzyme activities and metabolites. In the testis homogenate, hexokinase (HK), pyruvate kinase (PK), and lactate dehydrogenase (LDH) activities and lactate and pyruvate content were specifically detected by colorimetric assay at different absorbable wavelengths as the purchased kit (Nanjing Jiancheng Bioengineering Institute) indicated.

Quantitative real-time PCR ( $q P C R)$. As reported previously (22), total RNA was isolated from the testis and its quality was assessed by spectroscopy. Synthesis of cDNA was 
Table I. Primers for reverse transcription-quantitative PCR.

\begin{tabular}{lllr}
\hline Accession no. & Gene & Sequence of forward and reverse primers 5'-3' & Amplicon length (bp) \\
\hline AF121906.1 & SOD & F CTACCTTCCGGATAGAGGAT & 123 \\
NM_009804.2 & R TCCCTGTGATCTTGGATAAG & 120 \\
AF045768.1 & F TACACAAAGGTGTTGAACGA & 107 \\
X61093.1 & R GTGGACGTCAGTGAAATTCT & 117 \\
AF058054.1 & FLUT3 & R ACTTTCATCCATTTCCACAG & 119 \\
AF178954.1 & MCT2 & F AGATCCAGGAGATGAAGGAT & 120 \\
GU214026.1 & R GAGGACAATGGAGATGAGAA & 102 \\
& FCT4 & R AGAACTGGACAACACTCCAC & \\
& FAPDH & F GTGGTGAGCTATGCTAAGGA & \\
\end{tabular}

F, forward; R, reverse; SOD, superoxide dismutase; CAT, catalase; GPx, glutathione peroxidise; GLUT3, glucose transporter 3; MCT2, monocarboxylate transporter 2; MCT4, monocarboxylate transporter 4.

performed with the TransScript II One-Step gDNA Removal and cDNA Synthesis SuperMix Kit (Beijing Transgen Biotech Co., Ltd., Beijing, China), according to the manufacturer's protocols. Quantitative PCR analysis for gene expression level was performed by the SYBR-Green Assay System with the Applied Biosystems 7500 Real-Time PCR System (Applied Biosystems; Thermo Fisher Scientific, Inc., Waltham, MA, USA). The primers used in the present study are presented in Table I. PCR cycle parameters were $95^{\circ} \mathrm{C}$ for $15 \mathrm{sec}$ and $55^{\circ} \mathrm{C}$ for $1 \mathrm{~min}$, lasting for 40 cycles. The threshold line was set in the linear region of the plots above the baseline noise, and the value of the threshold cycle $\left(\mathrm{C}_{\mathrm{T}}\right)$ was determined as the cycle number at which the threshold line crossed the amplification curve. PCR without template or with template substituted with total RNA was used as a negative control to verify experimental results. After amplification, the specificity of the PCR was determined by both melting curve analysis and gel electrophoresis to verify that only a single product of the correct size was present. Data were normalized against GAPDH, and all samples were amplified for 3 replications. Data are presented as the average fold increase \pm standard error of mean (SEM).

Western blot analysis. Tissues were lysed in RIPA buffer (Promega Corporation, Madison WI, USA) containing protease inhibitor cocktail (Roche Diagnostics, Basel, Switzerland). The concentrations of total protein in the whole-cell lysate were determined by the Bradford assay. An equal amount $(20 \mu \mathrm{g})$ of protein in each sample was separated by $12 \%$ sodium dodecyl sulphate-polyacrylamide gel electrophoresis and then transferred to a polyvinylidene difluoride membrane (EMD Millipore, Bedford, MA, USA). The membrane was incubated with $5 \%(\mathrm{w} / \mathrm{v})$ skim milk in phosphate-buffered saline (PBS; $\mathrm{pH} 7.4)$ containing $0.05 \%$ Tween-20 (PBS-T) at $20^{\circ} \mathrm{C}$ for $1 \mathrm{~h}$ and then probed with anti-5' adenosine monophosphate-activated protein kinase (AMPK) antibody (1:800 dilution; cat.
Table II. Effect of EB on sperm quantity of mice (mean \pm SEM).

\begin{tabular}{lcc}
\hline $\begin{array}{l}\text { Dosages } \\
(\mathrm{mg} / \mathrm{kg})\end{array}$ & $\begin{array}{c}\text { Weight of cauda } \\
\text { epididymidis }(\mathrm{mg})\end{array}$ & $\begin{array}{c}\text { Sperm count } \\
\left(10^{6} / 100 \mathrm{mg}\right)\end{array}$ \\
\hline 0 & $12 \pm 16$ & $14.56 \pm 1.48$ \\
5 & $7 \pm 12^{\mathrm{a}}$ & $0 \pm 0^{\mathrm{b}}$ \\
10 & $6 \pm 11^{\mathrm{a}}$ & $0 \pm 0^{\mathrm{b}}$ \\
\hline
\end{tabular}

Data are expressed as the mean \pm SEM of 15 mice in each group, compared with the control; ${ }^{\mathrm{a}} \mathrm{P}<0.05,{ }^{\mathrm{b}} \mathrm{P}<0.01$. EB, oestradiol benzoate; SEM, standard error of mean.

no. ab32047, Abcam, Cambridge, MA, USA), anti-p-AMPK antibody (1:1,500 dilution; cat. no. ab23875, Abcam), and anti- $\beta$-actin antibody (1:1,000 dilution; cat. no. ab8227, Abcam) for $2 \mathrm{~h}$ at room temperature. The membrane was washed in PBS-T and then incubated with horseradish peroxidase-conjugated goat anti-rabbit IgG secondary antibody (dilution 1:1,500; cat. no. sc-2004; Santa Cruz Biotechnology, Inc., Santa Cruz, CA, USA) for $1 \mathrm{~h}$ at room temperature. Reactive proteins were detected using enhanced chemiluminscent and SuperSignal Chemiluminescent Substrates (Pierce; Thermo Fisher Scientific, Inc.). The protein intensity was semi-quantified using the ChemiDoc MP Imaging System (version 5.1.2; Bio-Rad Laboratories, Inc.).

Statistical analysis. Data were analysed using SPSS 17.0 software (SPSS, Inc., Chicago, IL, USA). All experimental data are presented as the mean \pm SEM. One-way analysis of variance (ANOVA) and Dunnett's post hoc test were employed when comparisons were performed between a control group and $>1$ experimental group to identify their differences. 
A

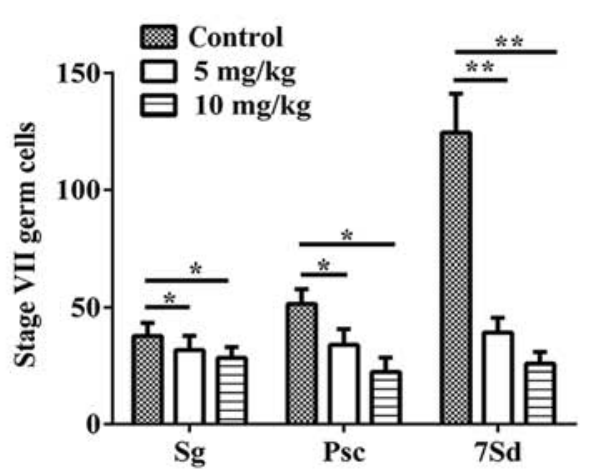

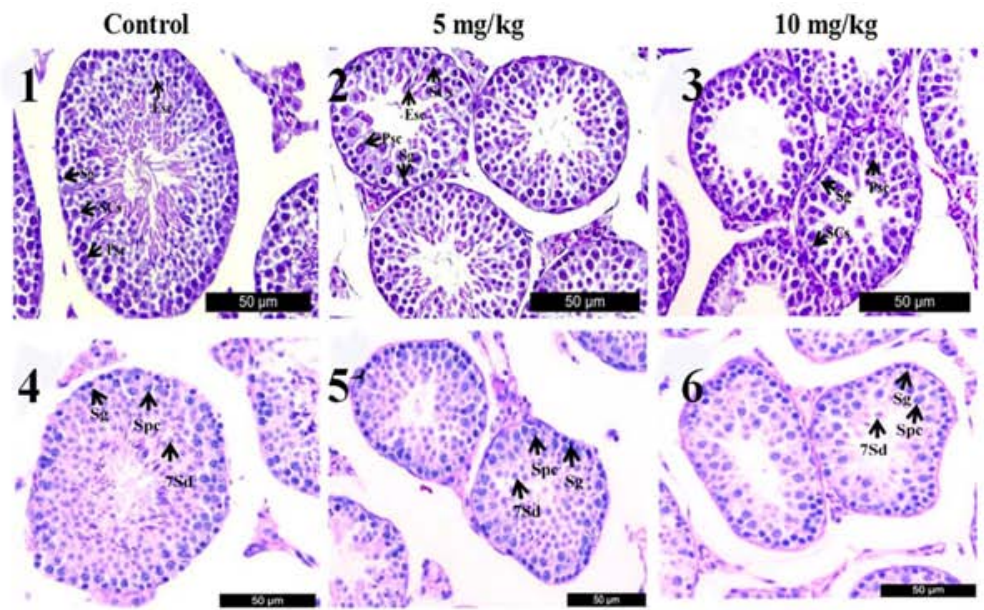

$5 \mathrm{mg} / \mathrm{kg}$

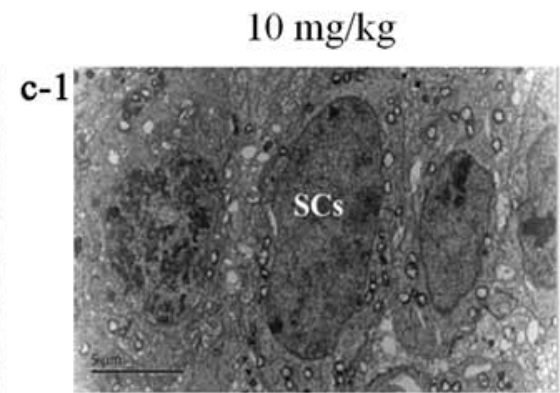

B

Control

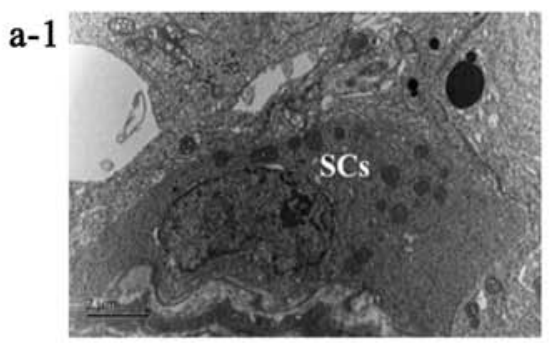

b-1

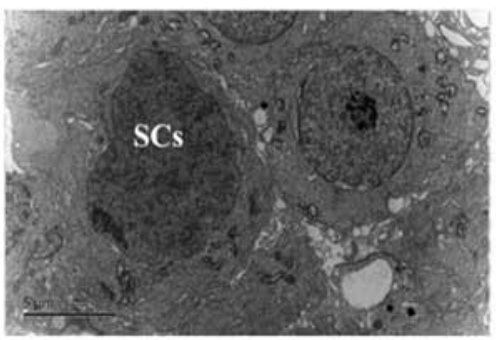

a-2

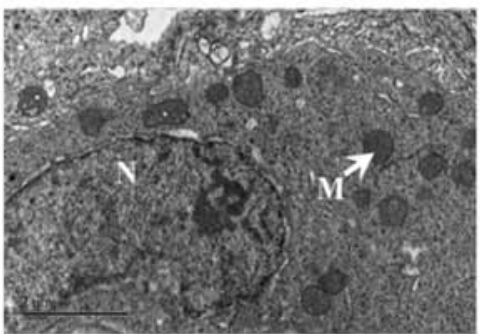

b-2

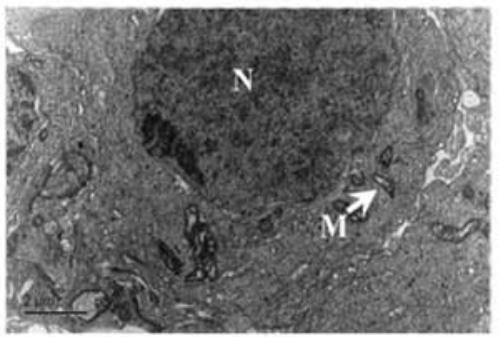

c-2

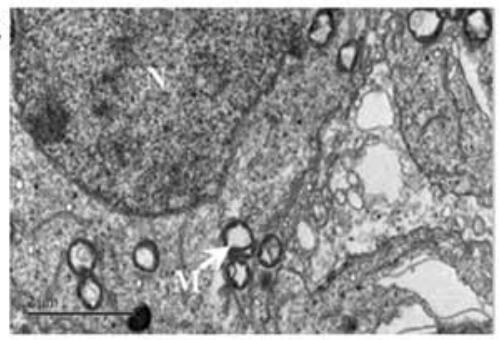

Figure 1. Effects of EB on the number of testicular cells and the ultrastructure of Sertoli cells. (A, left panel) The numbers of spermatogonia and spermatocytes at stage VII of the spermatogenic cycle in 100 seminiferous tubules. ${ }^{*} \mathrm{P}<0.05,{ }^{* *} \mathrm{P}<0.01$. (A, right panel) (1-3) testes stained with H\&E; (4-6) testes stained with PAS. Sg, Psc, 7Sd, and SCs are indicated by black arrows. (B) Control groups (a-1 and -2); mice treated with $5 \mathrm{mg} / \mathrm{kg} / \mathrm{day}$ oestradiol benzoate (b-1 and -2); mice treated with $10 \mathrm{mg} / \mathrm{kg} /$ day oestradiol benzoate (c-1 and -2). N, means cell nucleus; mitochondria are indicated by black arrows. EB, oestradiol benzoate; H\&E, haematoxylin and eosin; PAS, periodic acid-Schiff; Sg, spermatogonia; Psc, primer spermatocytes; 7Sd, step 7 spermatids; SCs, Sertoli cells.

A P-value $<0.05$ was considered to indicate a statistically significant result.

\section{Results}

EB causes male mice azoospermia. The weights of the cauda epididymides and sperm counts were recorded (Table II), which revealed that there was a significant decrease in caudal epididymis weight in EB-treated mice (both $\mathrm{P}<0.05$ ). As indicated by sperm suspension analysis, the control mice exhibited normal sperm counts; however, no sperm were observed in EB-treated mice (both $\mathrm{P}<0.01$ vs. control).

$\mathrm{H} \& \mathrm{E}$ and PAS staining were performed to reveal the morphology of spermatogenic cells at different developmental stages in the seminiferous tubules. Representative spermatogonium, primary spermatocyte, and step 7 spermatids were indicated by the black arrows (Fig. 1A, right). Through statistical analysis, it was determined that 5 and $10 \mathrm{mg} / \mathrm{kg}$ EB decreased all the number of spermatogonium $(\mathrm{P}<0.05)$, primary spermatocyte $(\mathrm{P}<0.05)$, and step 7 spermatids $(\mathrm{P}<0.05)$ in the seminiferous tubules (Fig. 1A, left).

Ultrastructural changes of Sertoli cells. The nuclei of SCs exhibited an irregular oval shape at the ultrastructural level, and the nuclei were prominent in most sections of the SCs (Fig. 1Ba-1). The electron-dense perinuclear heterochromatin clumps could also be observed in the SCs. The cytoplasm of SCs contained numerous mitochondria, which had a circular outline with an electron-dense matrix and complete cristae (Fig. 1Ba-2). The ultrastructure of SCs in EB-treated groups displayed irregular oval-shaped nuclei and electron-dense perinuclear heterochromatin clumps (Fig. 1Bb-1 and c-1). However, almost all SCs had marked alterations in mitochondria. In the $5 \mathrm{mg} / \mathrm{kg}$ EB-treated group, the mitochondria were transformed to vacuoles with irregular cristae (Fig. 1Bb-2); in the $10 \mathrm{mg} / \mathrm{kg}$ EB-treated group, the mitochondria became giant organelles with irregular cristae and vacuoles were clearly observable (Fig. 1Bc-2). 

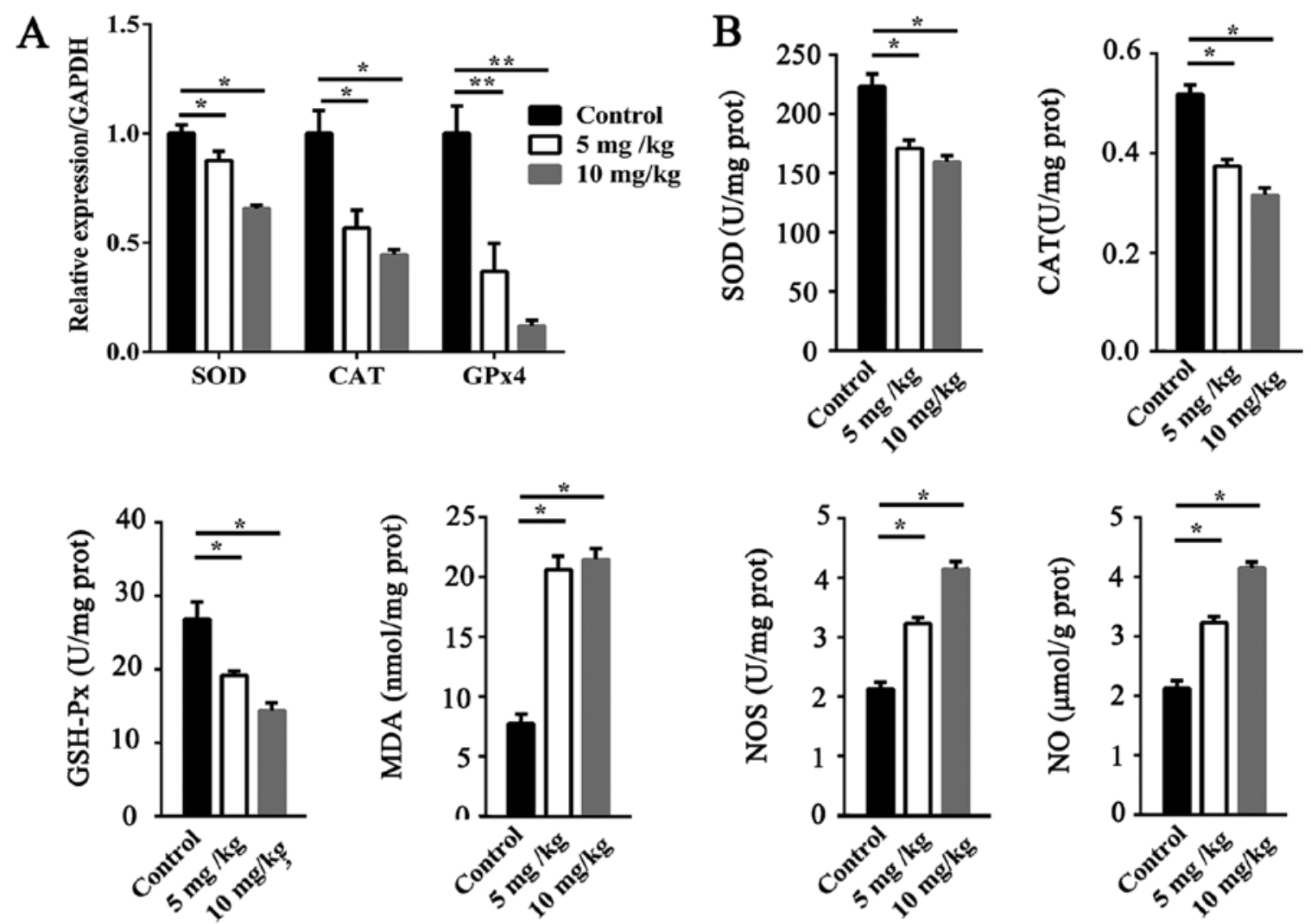

Figure 2. Effect of EB on antioxidative balance in testes. (A) SOD, CAT, and GPx4 mRNA levels in the testes. (B) Activities of SOD, CAT, and GPxs and NOS as well as the levels of MDA and NO in testes. Results are expressed as the means $\pm \mathrm{SEM}\left(\mathrm{n}=5\right.$ for each condition). ${ }^{*} \mathrm{P}<0.05$, $^{* *} \mathrm{P}<0.01$. EB, oestradiol benzoate; SOD, superoxide dismutase; CAT, catalase; GPx, glutathione peroxidise; NOS, nitric oxide synthase; MDA, malondialdehyde; NO, nitric oxide; SEM, standard error of mean.

Oxidative stress in the testis. Compared with the control group, the activities of SOD, CAT, and GSH-Px were significantly decreased $(\mathrm{P}<0.05$; Fig. $2 \mathrm{~B})$ by EB treatments, while the contents of MDA and NO as well as NOS activity $(\mathrm{P}<0.05$ or $\mathrm{P}<0.01$, Fig. $2 \mathrm{~B}$ ) were increased. In addition, the mRNA expression levels of SOD $(\mathrm{P}<0.05)$, CAT $(\mathrm{P}<0.05)$, and GSH-Px $(\mathrm{P}<0.01)$ in the EB-treated group were significantly reduced (Fig. 2A).

Metabolic profile of the testis after EB treatment. HPLC analysis confirmed that ATP content in EB-treated groups was significantly decreased compared with the control groups $(\mathrm{P}<0.05$; Fig. 3A), while the testicular glucose and pyruvate were increased $(\mathrm{P}<0.01$; Fig. $3 \mathrm{~B})$. The activity of AMPK is primarily assessed by the protein phosphorylation level. GLUT3, MCT2 and MCT4 are transporters. Their functions are mainly affected by their gene expression. Protein levels of AMPK and p-AMPK were decreased by EB in a dose-dependent manner (Fig. 3C). The p-AMPK/AMPK ratio was decreased by $5 \mathrm{mg} / \mathrm{kg} \mathrm{EB}(\mathrm{P}<0.05)$, but increased by $10 \mathrm{mg} / \mathrm{kg} \mathrm{EB}(\mathrm{P}<0.05)$. The relative mRNA expression of GLUT3, MCT2, and MCT4 is displayed in Fig. 3D. The mRNA expression level of GLUT3 was significantly upregulated by EB $(\mathrm{P}<0.05)$, whereas MCT2 and MCT4 expression in the testis was downregulated $(\mathrm{P}<0.05)$. There was no difference in the concentration of lactate between EB-treated and control groups (data not shown). The activities of HK and PK were significantly decreased by $\mathrm{EB}(\mathrm{P}<0.05$; Fig. $3 \mathrm{E})$, however the activity of LDH was almost unchanged between the 3 groups (data not shown).

\section{Discussion}

Environmental pollution by natural or chemically synthetic oestrogen has been confirmed to disrupt the normal function of male reproduction (23-25). Epidemiological studies have suggested a strong correlation between exposure to oestrogen and alterations to the reproductive system, infertility, and increased risk of seminomas and malformations (24). Our preliminary experimental study indicated that EB impaired spermatogenesis through apoptosis and ER signalling pathways (11). In agreement with previous studies, decreased sperm counts in male mice were observed following EB treatment. Exposure to EB decreased the number of spermatogonia, spermatocytes, and step 7 spermatids, which was similar to the effect caused by BPA (26). At the ultrastructural level, the transformation of SC mitochondria to vacuoles with irregular cristae in EB-treated groups indicated that EB damaged the structure of SC mitochondria and induced mitochondrial dysfunction. SCs are often referred to as 'nurse cells', responsible for providing energy and nutrition to support the growth and development of spermatogenic cells; therefore, the structural destruction of mitochondria in SCs is very likely to influence the energy supply to spermatogenic cells.

Oxidative damage induced by EB in the testis was also observed in the present study. Previous studies have revealed 

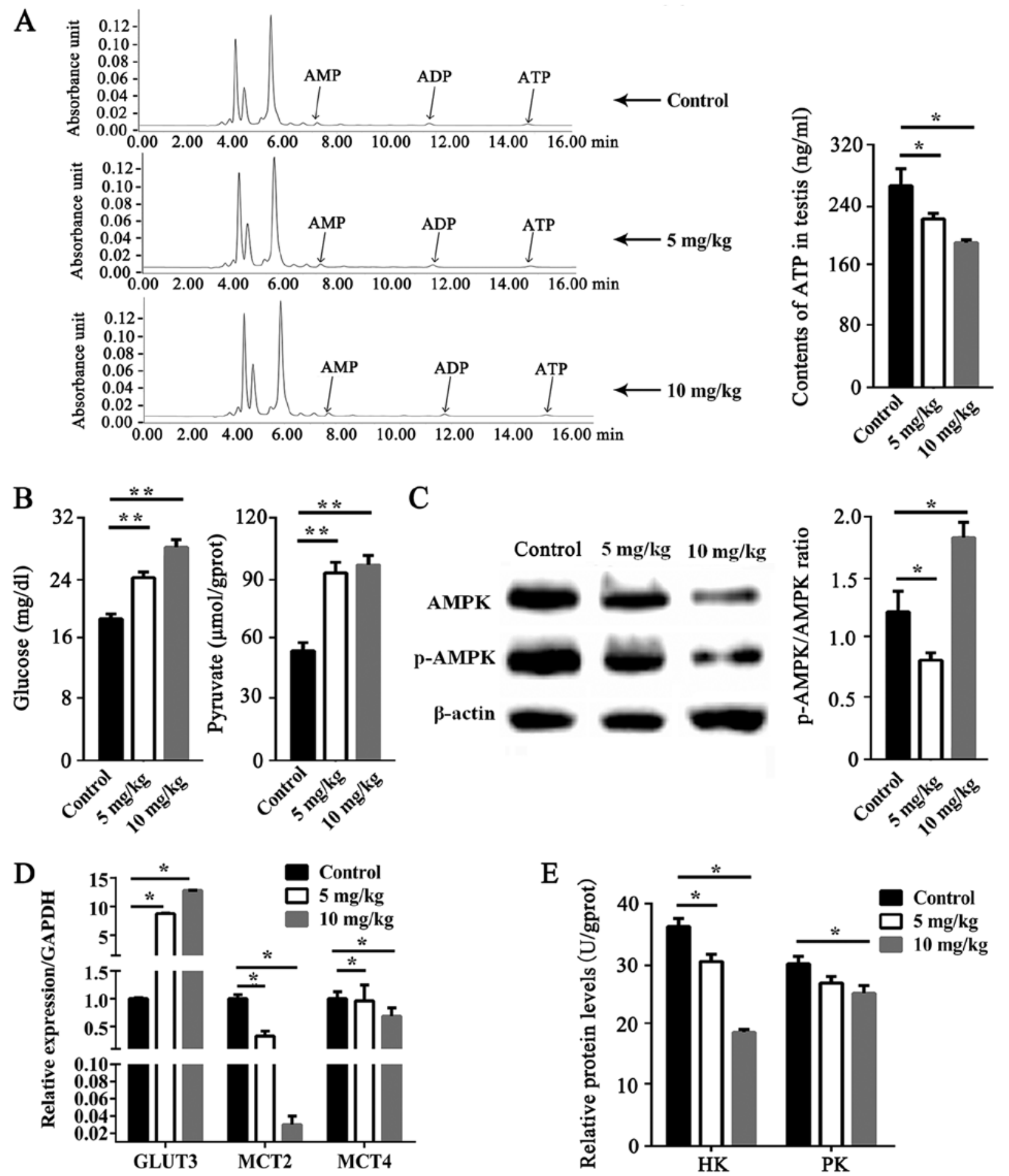

Figure 3. Effect of EB on testicular energy metabolism. (A) ATP content in mice testis. (B) Content of glucose and pyruvate in mice testis. (C) AMPK and p-AMPK protein levels. (D) mRNA levels of GLUT3, MCT2, and MCT4 in the testis. (E) Activities of HK and PK in mice testis. Results are expressed as the means \pm SEM ( $n=5$ for each condition). Relative to the control, ${ }^{*} \mathrm{P}<0.05,{ }^{* *} \mathrm{P}<0.01$. EB, oestradiol benzoate; ATP, adenosine triphosphate; AMPK, 5 ' adenosine monophosphate-activated protein kinase; GLUT3, glucose transporter 3; MCT2, monocarboxylate transporter 2; MCT4, monocarboxylate transporter 4; HK, hexokinase; PK, pyruvate kinase; SEM, standard error of mean.

that oral gavage quinestrol causes testicular damage via oxidative stress, as indicated by changes in MDA concentration and the activities of SOD and GSH-Px (21). The present results revealed that the activities of antioxidant enzymes including CAT, SOD, and GSH-Px in the testis of the EB-treated animals were significantly decreased, but the level of lipid peroxidation product (MDA) was increased. Decreased CAT and SOD activities impair the elimination of reactive oxygen species (ROS), which can lead to germ cell dysfunction or even death (27). GSH-Px can scavenge alkyl (R·), RO·, and ROO· radicals that may form from oxidized membrane components and protect the structure and function of testicular cells from oxidative damage (28). Thus, the depletion of testicular GSH-Px levels by EB may ultimately render testicular cells even more 
sensitive to oxidative stress. Polyunsaturated fatty acids are important components of the cell membrane, and they play an important role in the maintenance of membrane structure and functions. Endogenous MDA mainly results from lipid peroxidation of polyunsaturated fatty acids. Therefore, MDA is often used to assess the impairment of the cell membrane in response to oxidative species (29-31). The increase in MDA content of the EB-treated group indicated the impairment of the cellular membrane structure. Previous studies revealed that E2 induced NOS activation along with increased NO levels in cerebral and hepatic cells $(32,33)$. The present study revealed that NO and NOS were also significantly increased in the testis after EB treatment, which may aggravate damage to sperm cells.

Mitochondria are the main organelles that produce ROS; they can also be attacked by ROS in turn (34). It was thus suggested that the ultrastructural changes to the mitochondria in SCs may result from oxidative damage or direct impairment by toxic metabolites that are accumulated during metabolic disorder (35). Since ATP production can be impaired by oxidative stress (36), the decreased ATP content in the testis following EB treatment may be the result of EB disrupting ATP synthesis in SCs, ultimately leading to energy supply disorder in germ cells. Theoretically, ATP reduction could induce the activation of 5' adenosine monophosphate-activated protein kinase (AMPK); however, it was revealed that the expression of AMPK and p-AMPK protein was significantly decreased in mice testes. AMPK is a conserved sensor of cellular energy change and maintains energy balance by regulating ATP synthesis and consumption (37). Prior to the present study, there was no evidence that the expression of AMPK in the testes is affected by oestrogen. Furthermore, the causes of AMPK downregulation are still unclear and require further investigation. It was speculated that ROS is an important cause of the downregulation of AMPK. On the one hand, ROS has an impact on cell-signaling proteins (NF- $\mathrm{KB}, \mathrm{MAPKs}$, Keap1-Nrf2-ARE, and PI3K-Akt), ion channels and transporters $[\mathrm{Ca}(2+)$ and $\mathrm{mPTP}]$, and modifying protein kinase and ubiquitination/proteasome system, as indicated by a literature review (38), therefore it is possible that ROS downregulates AMPK by impacting other signaling pathways or ubiquitination; on the other hand, overproduced ROS can directly interact with proteins, resulting in the impairment of protein functions. Theoretically, ROS-mediated damage of molecules implicated in the transcriptional regulation of AMPK may cause its downregulation.

Spermatogenesis is highly dependent on metabolic cooperation between SCs and germ cells in growth. SCs produce lactate primarily from glucose, and the rate-limiting step is the membrane passage of glucose from the extracellular space via specific GLUTs $(14,39)$. However, $17 \beta$-oestradiol (E2) downregulated the transcript levels of GLUT1 and GLUT3 in SCs in vitro (16). In contrast to previous research that revealed that BPA and oestradiol decrease testicular glucose levels (40), the present study found that EB increased glucose levels and GLUT3 mRNA expression in testis. Exogenous oestrogen may exert a different effect on glucose metabolism. With the assistance of HK and PK, glucose can be transformed to pyruvate, which is used as a substrate in the tricarboxylic acid cycle in mitochondria, or reduced to lactate in the cytoplasm $(41,42)$. The present data revealed that the amount of lactate in the testis was not changed by EB, suggesting pyruvate was not used for the production of lactate in any considerable quantity. In addition, mitochondria in SCs were damaged after EB treatment, as indicated by their anomalous structure and decreased ATP production. Therefore, pyruvate could not be oxidized in the tricarboxylic acid cycle, and thus it accumulated in the testis. High levels of pyruvate adversely affect spermatogenesis $(43,44)$. Although EB increased glucose levels in the testis, it was not effectively used for producing ATP; the question of why pyruvate was not transformed to lactate in considerable quantities is an interesting one. It was revealed that the transcriptional levels of both MCT2 and MCT4 were significantly downregulated in the EB-treated group. The lactate produced by SCs can be exported by MCT4, and the lactate in the intratubular fluid is taken up by germ cells through MCT2 (45). Therefore, decreased MCT2 and MCT4 levels inhibit the export of lactate from SCs and its import to germ cells. The accumulation of lactate in SCs possibly prevents the transformation of pyruvate to lactate by a negative feedback mechanism.

Based on our data, the detrimental effect of EB on male reproductive function is associated with both the overproduction of oxidative species and the alteration of testicular metabolic cooperation. Thus, additional supplement of conventional antioxidants may not be sufficient to eliminate the detrimental effect of EB, although the alteration of testicular metabolic cooperation was partly due to the detrimental function of ROS. The improvement of the energy metabolism of testis in addition to the supplement of an antioxidant after exposure to EB is suggested.

Collectively, the present results revealed that the exposure of male mice to EB induced azoospermia through oxidative damage and the disruption of testicular metabolic cooperation between SCs and germ cells. It is likely that EB downregulation of MCT2 and MCT4 is the molecular basis underlying the metabolic dysfunction of SCs and germ cells. Further study is required to ascertain whether the resumption of MCT2 and MCT4 expression can antagonise the destructive effect of EB on spermatogenesis.

\section{Acknowledgements}

Not applicable.

\section{Funding}

The present study was supported by the China National Natural Science Fund (grant nos. 31460282 and 81860733), The Science and Technology Fund of Guizhou province (grant. no. Qian Basic[2019]1344), the Talent Growth Project of Youth Science and Technology of Guizhou Province Education Department [no. (2016)210], and the PhD Start-up Fund of Zunyi Medical University (no. F-861).

\section{Availability of data and materials}

The datasets used and/or analyzed during the current study are available from the corresponding author on reasonable request. 


\section{Authors' contributions}

$\mathrm{XL}, \mathrm{ZL}$, and YR were responsible for the experimental design. ZL, YR and JL performed the experiments of the study and wrote the manuscript. HT, FD, XY and YZ analyzed the data. SZ and QL interpreted and collected the data, and revised the manuscript. All authors read and approved the manuscript and agree to be accountable for all aspects of the research in ensuring that the accuracy or integrity of any part of the work are appropriately investigated and resolved.

\section{Ethics approval and consent to participate}

The study was approved by The Ethics Committee of Zunyi Medical University (Guizhou, China). The present study was approved and monitored by the Animal Experiments Ethical Review Committee of the Zunyi Medical University (no. ZMU210500326). All procedures strictly adhered to the National Institutes of Health guidelines for the care and use of animals (18).

\section{Patient consent for publication}

Not applicable.

\section{Competing interests}

The authors declare that they have no competing interests.

\section{References}

1. O'Donnell L, Robertson KM, Jones ME and Simpson ER Estrogen and spermatogenesis. Endocr Rev 22: 289-318, 2001.

2. Pavlovich CP, King P, Goldstein M and Schlegel PN: Evidence of a treatable endocrinopathy in infertile men. J Urol 165: 837-841, 2001.

3. Jensen TK, Toppari J, Keiding N and Skakkebaek NE: Do environmental estrogens contribute to the decline in male reproductive health? Clin Chem 41: 1896-1901, 1995.

4. Li X, Li H, Jia L, Li X and Rahman N: Oestrogen action and male fertility: Experimental and clinical findings. Cell Mol Life Sci 72: 3915-3930, 2015.

5. Giwercman A: Estrogens and phytoestrogens in male infertility. Curr Opin Urol 21: 519-526, 2011.

6. LaRocca J, Boyajian A, Brown C, Smith SD and Hixon M: Effects of in utero exposure to Bisphenol A or diethylstilbestrol on the adult male reproductive system. Birth Defects Res B Dev Reprod Toxicol 92: 526-533, 2011.

7. Vitku J, Sosvorova L, Chlupacova T, Hampl R, Hill M, Sobotka V, Heracek J, Bicikova M and Starka L: Differences in bisphenol A and estrogen levels in the plasma and seminal plasma of men with different degrees of infertility. Physiol Res 64 (Suppl 2): S303-S311, 2015.

8. Chaki SP, Misro MM, Gautam DK, Kaushik M, Ghosh D and Chainy GB: Estradiol treatment induces testicular oxidative stress and germ cell apoptosis in rats. Apoptosis 11: 1427-1437, 2006.

9. Walker DM, Kermath BA, Woller MJ and Gore AC: Disruption of reproductive aging in female and male rats by gestational exposure to estrogenic endocrine disruptors. Endocrinology 154: 2129-2143, 2013

10. Reilly MP, Weeks CD, Topper VY, Thompson LM, Crews D and Gore AC: The effects of prenatal PCBs on adult social behavior in rats. Horm Behav 73: 47-55, 2015

11. Lei X, Cui K, Liu Q, Zhang H, Li Z, Huang B and Shi D: Exogenous estradiol benzoate induces spermatogenesis disorder through influencing apoptosis and oestrogen receptor signalling pathway. Reprod Domest Anim 51: 75-84, 2016.
12. Cairns RA, Harris IS and Mak TW: Regulation of cancer cell metabolism. Nat Rev Cancer 11: 85-95, 2011.

13. Patnaik A, Locasale JW and Cantley LC: Cancer cell metabolism: Springer US, 76: pp299-311, 2012.

14. Rato L, Alves MG, Socorro S, Duarte AI, Cavaco JE and Oliveira PF: Metabolic regulation is important for spermatogenesis. Nat Rev Urol 9: 330-338, 2012.

15. Oliveira PF and Alves MG: Sertoli Cell Metabolism and Spermatogenesis. In: Springerbriefs in Cell Biology. 1st edition. Springer International Publishing, p98, 2015.

16. Martins AD, Alves MG, Simões VL, Dias TR, Rato L, Moreira PI, Socorro S, Cavaco JE and Oliveira PF: Control of Sertoli cell metabolism by sex steroid hormones is mediated through modulation in glycolysis-related transporters and enzymes. Cell Tissue Res 354: 861-868, 2013.

17. Putz O, Schwartz CB, Kim S, LeBlanc GA, Cooper RL and Prins GS: Neonatal low- and high-dose exposure to estradiol benzoate in the male rat: I. Effects on the prostate gland. Biol Reprod 65: 1496-505, 2001.

18. National Research Council (US) Institute for Laboratory Animal Research. Guide for the Care and Use of Laboratory Animals. Astronomy \& Astrophysics 327: 963-965, 2004.

19. Gouyandeh J, Modaresi M, Mansouri S and Najafabadi FY: Long-term effects of betamethasone on epididymal tissue, epididymal sperm counts and fertility in male mice. J Chem Health Risks 5: 295-300, 2015.

20. Clermont Y and Perey B: The stages of the cycle of the seminiferous epithelium of the rat: Practical definitions in PA-Schiff-hematoxylin and hematoxylin-eosin stained sections. Rev Can Biol 16: 451-462, 1957.

21. Nikolaidou B, Nouris C, Lazaridis A, Sampanis C and Doumas M: Diabetes mellitus and erectile dysfunction: Springer International Publishing, pp119-128, 2015.

22. Welborn JP, Davis MG, Ebers SD, Stodden GR, Hayashi K, Cheatwood JL, Rao MK and MacLean JA III: Rhox8 ablation in the sertoli cells using a tissue-specific RNAi approach results in impaired male fertility in mice. Biol Reprod 93: 8, 2015.

23. Sharpe RM: Environmental estrogens and male infertility. Pure App Chem 70: 1685-1701, 1998.

24. Rochester JR: Bisphenol A and human health: A review of the literature. Reprod Toxicol 42: 132-155, 2013.

25. Rao MV and Chinoy NJ: Effect of oestradiol benzoate on reproductive organs and fertility in the male rat. Eur J Obstet Gynecol Reprod Biol 15: 189-198, 1983.

26. Jin P, Wang X, Chang F, Bai Y, Li Y, Zhou R and Chen L: Low dose bisphenol A impairs spermatogenesis by suppressing reproductive hormone production and promoting germ cell apoptosis in adult rats. J Biomed Res 27: 135-144, 2013.

27. Samhan-Arias AK, Tyurina YY and Kagan VE: Lipid antioxidants: Free radical scavenging versus regulation of enzymatic lipid peroxidation. J Clin Biochem Nutr 48: 91-95, 2011.

28. Goc Z, Szaroma W, Kapusta E and Dziubek K: Protective effects of melatonin on the activity of SOD, CAT, GSH-Px and GSH content in organs of mice after administration of SNP. Chin J Physiol 60: 1-10, 2017.

29. Omar SS, Aly RG and Badae NM: Vitamin E improves testicular damage in streptozocin-induced diabetic rats, via increasing vascular endothelial growth factor and poly(ADP-ribose) polymerase-1. Andrologia 50, 2018.

30. Wiktorowska-Owczarek A, Berezińska M and Nowak JZ: PUFAs: Structures, metabolism and functions. Adv Clin Exp Med 24: 931-941, 2015.

31. Schroeder F, Kier AB and Sweet WD: Role of polyunsaturated fatty acids and lipid peroxidation in LM fibroblast plasma membrane transbilayer structure. Arch Biochem Biophys 276: 55-64, 1990.

32. Sakamoto M, Ueno T, Nakamura T, Sakata R, Hasimoto O, Torimura $\mathrm{T}$ and Sata M: Improvement of portal hypertension and hepatic blood flow in cirrhotic rats by oestrogen. Eur J Clin Invest 35: 220-225, 2015.

33. Nevzati E, Shafighi M, Bakhtian KD, Treiber H, Fandino J and Fathi AR: Estrogen induces nitric oxide production via nitric oxide synthase activation in endothelial cells. Acta Neurochir Suppl 120: 141-145, 2015.

34. Al-Gubory KH: Mitochondria: Omega-3 in the route of mitochondrial reactive oxygen species. Int J Biochem Cell Biol 44: 1569-1573, 2012

35. Stepien KM, Heaton R, Rankin S, Murphy A, Bentley J, Sexton D and Hargreaves IP: Evidence of oxidative stress and secondary mitochondrial dysfunction in metabolic and non-metabolic disorders. J Clin Med 6: pii: E71, 2017. 
36. Liang H, Remmen HV, Frohlich V, Lechleiter J, Richardson A and Ran Q: GSH-Px4 protects mitochondrial ATP generation against oxidative damage. Biochem Biophys Res Commun 356 893-898, 2007.

37. Ke R, Xu Q, Li C, Luo L and Huang D: Mechanisms of AMPK in the maintenance of ATP balance during energy metabolism. Cell Biol Int 42: 384-392, 2018.

38. Zhang J, Wang X, Vikash V, Ye Q, Wu D, Liu Y and Dong W: Ros and ros-mediated cellular signaling. Oxid Med Cell Longev 2016: 4350965, 2016.

39. Kishimoto A, Ishiguro-Oonuma T, Takahashi R, Maekawa M, Toshimori K, Watanabe M and Iwanaga T: Immunohistochemical localization of GLUT3, MCT1, and MCT2 in the testes of mice and rats: The use of different energy sources in spermatogenesis. Biomed Res 36: 225-234, 2015.

40. D'Cruz SC, Jubendradass R and Mathur PP: Bisphenol A induces oxidative stress and decreases levels of insulin receptor substrate 2 and glucose transporter 8 in rat testis. Reprod Sci 19: 163-172, 2012.
41. Rato L, Alves MG, Dias TR, Cavaco JE and Oliveira PF: Testicular metabolic reprogramming in neonatal streptozotocininduced type 2 diabetic rats impairs glycolytic flux and promotes glycogen synthesis. J Diabetes Res 2015: 973142, 2015.

42. Tavares RS, Portela JMD, Sousa MI, Mota PC, Ramalho-Santos J and Amaral S: High glucose levels affect spermatogenesis: An in vitro approach. Reprod Fertil Dev 29: 1369-1378, 2016.

43. Oliveira PF and Alves MG: Modulation of sertoli cell metabolism: Springer International Publishing, pp57-71, 2015.

44. Oishi S: Effects of phthalic acid esters on testicular mitochondrial functions in the rat. Arch Toxicol 64: 143-147, 1990.

45. Oliveira PF, Martins AD, Moreira AC, Cheng CY and Alves MG: The warburg effect revisited-lesson from the sertoli cell. Med Res Rev 35: 126-151, 2015. 